\title{
Gene cascade analysis in human granulosa tumor cells (KGN) following exposure to high levels of free fatty acids and insulin
}

\author{
Patricia G. Tremblay, Chloé Fortin and Marc-André Sirard* (1)
}

\begin{abstract}
Maternal metabolic disorders such as obesity and diabetes are detrimental factors that compromise fertility and the success rates of medically assisted procreation procedures. During metabolic stress, adipose tissue is more likely to release free fatty acids (FFA) in the serum resulting in an increase of FFA levels not only in blood, but also in follicular fluid (FF). In humans, high concentrations of palmitic acid and stearic acid reduced granulosa cell survival and were associated with poor cumulus-oocyte complex (COC) morphology. Obesity and high levels of circulating FFA were also causatively linked to hampered insulin sensitivity in cells and compensatory hyperinsulinemia. To provide a global picture of the principal upstream signaling pathways and genomic mechanisms involved in this metabolic context, human granulosa-like tumor cells (KGN) were treated with a combination of palmitic acid, oleic acid, and stearic acid at the higher physiological concentrations found in the follicular fluid of women with a higher body mass index (BMI) $\left(\geq 30.0 \mathrm{~kg} / \mathrm{m}^{2}\right.$ ). We also tested a high concentration of insulin alone and in combination with high concentrations of fatty acids. Transcription analysis by RNA-seq with a cut off for fold change of 1.5 and p-value 0.05 resulted in thousands of differentially expressed genes for each treatment. Using analysis software such as Ingenuity Pathway Analysis (IPA), we were able to establish that high concentrations of FFA affected the expression of genes mainly related to glucose and insulin homoeostasis, fatty acid metabolism, as well as steroidogenesis and granulosa cell differentiation processes. The combination of insulin and high concentrations of FFA affected signaling pathways related to apoptosis, inflammation, and oxidative stress. Taken together, our results provided new information on the mechanisms that might be involved in human granulosa cells exposed to high concentrations of FFA and insulin in the contexts of metabolism disorders.
\end{abstract}

Keywords: Granulosa cells, Ovary, Signaling, Insulin signaling, Free fatty acid signaling, Metabolic disease

\section{Background}

The increasing prevalence of metabolic syndrome worldwide and its association with adverse health effects, including impaired reproductive function in women, have become issues of concern over the past decade. Maternal metabolic disorders such as obesity and

*Correspondence: Marc-Andre.Sirard@fsaa.ulaval.ca

Centre de Recherche en Reproduction, Développement et Santé

Intergénérationnelle, Faculté des Sciences de l'Agriculture et de

I'Alimentation, Département des Sciences Animales, Université Laval,

Québec, QC G1V 0A6, Canada diabetes are detrimental factors that compromise fertility and the success rates of medically assisted procreation (MAP) procedures [1, 2]. Accumulating evidence in several animal studies, especially the negative energy balance (NEB) model in bovine, contributed to indicate that free fatty acids (FFA) are key molecules associated with impaired cumulus-oocyte-complex (COC) morphology and impaired oocyte developmental competence and metabolism [3-11]. Free fatty acids act as cellular energy sources, essential components in membrane biogenesis, are involved in granulosa cell steroidogenesis, in original author(s) and the source, provide a link to the Creative Commons licence, and indicate if changes were made. The images or other third party material in this article are included in the article's Creative Commons licence, unless indicated otherwise in a credit line to the material. If material is not included in the article's Creative Commons licence and your intended use is not permitted by statutory regulation or exceeds the permitted use, you will need to obtain permission directly from the copyright holder. To view a copy of this licence, visit http://creativecommons.org/licenses/by/4.0/. The Creative Commons Public Domain Dedication waiver (http://creativeco mmons.org/publicdomain/zero/1.0/) applies to the data made available in this article, unless otherwise stated in a credit line to the data. 
addition to being powerful signaling molecules $[12,13]$. Elevated levels of FFA in circulation is a major characteristic of metabolic stress in human and bovine $[5,6,9$, $14,15]$. During metabolic stress such as obesity or diabetes, adipose tissue is more likely to release fatty acids in the serum resulting in increased FFA levels, not only in blood, but also in follicular fluid (FF) [11]. Recent studies in human and bovine showed that levels of FFA in blood were correlated with concentrations of FFA in follicular fluid [5, 6, 9, 16-18]. Analysis of fatty acids (FA) in human follicular fluid lipid fractions showed that FFA reflected the Body Mass Index (BMI) in women which was positively correlated with increasing FFA in ovarian follicular fluid $[3,15]$. Palmitic acid (C16:0) (PA), stearic acid (C18:0) (SA), and (C18:1) oleic acid (OA) were among the most abundant FFA in lipid fractions of human and bovine FF $[5,6,15]$. In humans, high concentrations of PA and SA reduced granulosa cell survival through the metabolism of the acyl-CoA forms [7]. Moreover, the $\mathrm{COC}$ of women with higher follicular FFA at oocyte aspiration tended to have poor morphology [5]. In bovine models, elevated concentrations of non-esterified fatty acids (NEFA), including saturated PA and SA, jeopardized granulosa cell viability and reduced oocyte developmental competence [3, 4, 6, 8, 10, 14, 19, 20]. Obesity and high levels of circulating NEFA were also causatively linked to hampered insulin sensitivity in cells and compensatory hyperinsulinemia [21, 22]. A higher BMI in women was significantly associated with increased levels of insulin in FF $[15,18]$. As reviewed by Purcell and Moley, insulin is involved in various granulosa cell functions such as proliferation, apoptosis, and steroidogenesis [23]. Moreover, periconceptional hyperinsulinemia is associated with obesity and may impair several granulosa cell functions such as estradiol production and FSHR expression, thereby impairing the response to fertility treatments [24].

Studying the specific effects of NEFA is a very difficult task using in vivo experimentation as follicular dynamics result in a constantly changing transcriptome. Therefore, to provide a global picture of the principal upstream signaling pathways and genomic mechanisms involved in the metabolic contexts described above, human granulosa-like tumor cells (KGN) were treated with a combination of PA, OA, and SA at the higher physiological concentrations found in the follicular fluid of women with higher BMI $\left(\geq 30.0 \mathrm{~kg} / \mathrm{m}^{2}\right)$ [15]. We also tested a high concentration of insulin alone and in combination with high concentrations of fatty acids [25]. The KGN cells, which are derived from a stage- 3 diagnosed granulosa cell tumor removed from a 63-year-old Japanese woman in 1984, are believed to have originated from a dominant follicle at the antral or pre-antral stage. These cells bear functional FSH receptors and share other similarities with ovarian granulosa cells in vivo, including cAMP-inducible aromatase expression. Therefore, these cells represent a unique system for the characterization of signaling pathways involved in human folliculogenesis [26]. Our study is, to our knowledge, the first to use a high-throughput approach to profile the transcriptional responses of human granulosa cells to this particular context of metabolic syndrome. Using this specific in vitro model also allows the main signalling pathways to be dissected in response to these three main free fatty acids either alone or in combination with insulin. Therefore, this study should be regarded as a reference for further in-depth research on major canonical pathway as well as major hub genes that could be involved in the response to human granulosa cells to such metabolic challenges.

\section{Methods}

\section{Human granulosa-like tumor cell line (KGN)}

The granulosa cell line KGN, a steroidogenic human ovarian granulosa cell line, was purchased from the RIKEN Bioresource Centre (Tsukuba, Japan). This cell line maintained physiological characteristics of ovarian granulosa cells, including the expression of functional FSH receptors and steroidogenic activity such as estradiol production in response to FSH stimulation [26]. The cells were cultured in DMEM/F12 medium (Life technologies) supplemented with $10 \%$ foetal bovine serum (Corning), 100X Penicillin-Streptomycin $(10,000 \mathrm{U} / \mathrm{mL}$ ) (Life technologies) in an atmosphere of $5 \% \mathrm{CO}_{2} / 95 \% \mathrm{O}_{2}$ at $37{ }^{\circ} \mathrm{C}$. According to the Human Research Ethics Committee of Laval University (CÉRUL), a research ethics board (REB) review was not required to work with the KGN cell line.

\section{NEFA treatments}

The concentrations of non-esterified fatty acids (NEFA) in the follicular fluid of obese women are significantly correlated with BMI, with the most abundant being palmitic acid (PA, 16:0), stearic acid (SA, 18:0), and oleic acid (OA, 18:1) [15]. To mimic the physiological metabolic conditions found in obese women and to be able to characterize the transcriptomic profile of KGN cells exposed to metabolic challenges similar to obesity, three conditions were set up (Table 1). We first assessed the consequences of exposure of KGN cells to a combination of free fatty acids found in higher concentrations in obese women on their transcriptomic profile. We also assessed the transcriptomic profiles of KGN cells exposed to a high concentration of insulin alone and in combination with high concentrations of fatty acids in order to mimic the insulin resistance that is often observed with obesity (Table 1). 
Table 1 Fatty acids and insulin concentrations for each experimental condition

\begin{tabular}{lll}
\hline Treatment & Culture media & Total FFAs \\
\hline CTRL & - & - \\
INSULIN & $100 \mathrm{ng} / \mathrm{mL}$ insulin & - \\
HIGH FAT (HF) & $\mathrm{PA} 75 \mu \mathrm{M}+\mathrm{SA} 25 \mu \mathrm{M}+$ OA 100 & $200 \mu \mathrm{M}$ \\
& $\mu \mathrm{M}$ & \\
HIGH FAT insulin (HFIns) & $\mathrm{PA} 75 \mu \mathrm{M}+\mathrm{SA} 25 \mu \mathrm{M}+\mathrm{OA} 100$ & $200 \mu \mathrm{M}$ \\
& $\mu \mathrm{M}+100 \mathrm{ng} / \mathrm{mL}$ insulin & \\
\hline
\end{tabular}

\section{Preparation of NEFA treatments}

The DMEM medium was first supplemented with $1 \%$ low fatty acid bovine serum albumin (BSA) (ABFF-100G, MP Biomedicals, Auckland, NZ) in order to improve fatty acid solubility. The fatty acids, PA (product P0500), SA (product S-4751), and OA (product T7140), all purchased from Sigma-Aldrich (St. Louis, MO), were prepared in stock solutions in ethanol $100 \%(\mathrm{ETOH})$ at concentrations of $225 \mathrm{mM}, 75 \mathrm{mM}$, and $300 \mathrm{mM}$, respectively. The fatty acid solutions were vortexed for 4 to $5 \mathrm{~min}$ before being added to the medium at working concentrations. The final medium mix was incubated in an atmosphere of $5 \% \mathrm{CO}_{2} / 95 \% \mathrm{O}_{2}$ at $37{ }^{\circ} \mathrm{C}$ for $24 \mathrm{~h}$ before being sonicated for 5 to $6 \mathrm{~min}$ in a small bath sonicator. Human insulin solution (Sigma-Aldrich product I9278) was added directly to the appropriate well at the time of treatment.

\section{Cell culture}

The KGN cells were thawed on day 1, placed in a cell culture flask ( $75 \mathrm{~cm}^{3}$, Sigma-Aldrich), grown up to $80 \%$ confluence, and sub-cultured on day 4 . On day 7 , viable cells were seeded in a six-well plate at a density of $3 \times 10^{5}$ per well in $3 \mathrm{ml}$ of medium and grown for $72 \mathrm{~h}$ to obtain full confluence. For all experimental conditions, the medium was then replaced with DMEM/F12 containing antibiotics, $100 \mathrm{nmol} \mathrm{L}^{-1}$ of 4-androstene-3,17-dione (product A9630, Sigma-Aldrich, St. Louis, MO) and 1\% of low fatty acid BSA. Plates were incubated for $24 \mathrm{~h}$ in a humidified incubator at $37{ }^{\circ} \mathrm{C}$ in 5\% CO2:95\% air after adding either ethanol (less than $0.1 \%$ of the culture volume) as a control or the fatty acid combination described above with or without the addition of human insulin. Control wells received the same volume of ethanol as the test groups.

\section{RNA purification and deep sequencing}

Total RNA was isolated using the Norgen's RNA/DNA Purification Kit (Cat. 48,700, Norgen Biotek Corporation, Canada) according to the manufacturer's instructions. Total RNA integrity and concentration were assessed on a 2100-Bioanalyzer (Agilent Technologies, Palo Alto,
CA) and the RNA Integrity Number (RIN) was 10 for all the samples. For each treatment, $270 \mathrm{ng}$ of total RNA was used for mRNA isolation (90 ng from each biological replicate). As described in a previous study, mRNA was isolated from total RNA using the NEBNext Poly (A) mRNA Magnetic Isolation Module (E7490S; NEB) and was fragmented to a mean size of $200 \mathrm{nt}$. Fragments were reverse transcribed to generate double-stranded cDNA and converted to a paired-end library using the NEBNext Ultra RNA Library Prep kit for Illumina (E7530S; NEB) according to the manufacturer's instructions and using Agencourt AMPure XP beads and NEBNext Mutliplex Oligos for Illumina (set1, E7335S; NEB) [27]. The libraries were sent to the Génome Québec Innovation Centre at McGill University (Montreal, Quebec, Canada) for quality control tests and then pooled at equimolar concentrations and sequenced on Illumina HiSeq4000 in paired-end mode with 100 base pair reads (PE100) to a depth between 53-69 million reads.

\section{Transcriptome assembly and expression level estimate from read counts}

Ensembl (release 91) was used as the source of annotated genes and transcript isoforms.Using Trimmomatic [28], sequencing adapters were removed and base calls with a quality score below 30 were removed from the end of the reads [28]. Only reads with a minimum length of 32 nt were retained for further processing. The abundance of all transcripts described in release 91 of ENSEMBL cdna gene annotation was estimated by pseudoalignment using kallisto [29]. Differential expression of genes was then assessed using pairwise comparisons in edgeR [30]. Because we did not have replicates, dispersion within edgeR was evaluated by grouping samples for similar comparisons (first for control, then for high fat, high fat/ insulin and insulin alone) and dropping the factor with the lowest impact, as suggested by the edgeR manual. The sequence data produced in this study were submitted to NCBI GEO under accession number GSE161914. As described in a previous study, normalized data were sorted for significance and then filtered according to the Transcript Support Level (TSL) used by the Ensembl gene annotation system [27]. This annotation system is a method to highlight the well supported and poorly supported transcript models for users. The method relies on the comparison of the mRNA and EST alignments to the GENCODE transcripts, and the transcripts are scored according to how well the alignment match over their full length. Differentially expressed genes selected for the present analysis were assigned to the evaluated annotations tsl1 which means that all splice junctions of the transcript were supported by at least one non-suspect mRNA. 


\section{Results}

\section{Differentially expressed genes in treatments}

Using KGN cells and RNA-seq technology, we performed transcriptome analysis of three different treatments of fatty acids combination at high physiological concentration and high concentration of insulin in combination or alone. For this analysis INS treatment, HF treatment and HFIns treatment were all individually compared to the control group using pairwise comparisons. Following gene expression level analysis, 1,615 up- and down-regulated differentially expressed genes (DEGs) were mapped and used in the insulin treatment (INS) for subsequent functional analysis. Totals of 1,700 DEGs and 1,634 DEGs were mapped for the high fat (HF) and high fat-insulin (HFIns) treatments, respectively. Curated lists of the first 100 most significant upregulated and downregulated DEGs for each treatment are available in supplemental data (Supplemental Table S1-S6). To provide a global picture of the principal upstream signaling pathways and genomic mechanisms involved in the treatments, functional analysis was conducted using the Ingenuity Pathway Analysis (IPA) software which is a web-based software that allows the analysis and interpretation of data derived from omics experiments. Comparing our dataset to the Ingenuity Knowledge Base which organizes biological interactions and functional annotations, and attributes a probability of association between genes in the dataset and biological functions, we were able to extract the major biological functions as well as potential upstream regulators in our system.

\section{Major canonical pathways related to insulin and fatty acid signaling}

The lists of DEGs from RNAseq data analysis of each treatment were separately uploaded into the IPA software and analyzed for the major biological functions that were the most significant to our dataset. A complete list of the significant canonical pathways affected by each treatment and identified by IPA is available in supplemental data (Supplemental table S7-S9). Table 2 presents several of the most significantly affected canonical pathways identified by IPA software for the Ins, HF and HFIns treatments (Table 2). The level of significance was measured by the ratio of the number of genes in our dataset that matched a given pathway over the total number of genes listed for this given pathway in the Ingenuity Knowledge Base. A p-value was also calculated with the Fisher's exact test to assess the probability of association between the gene's dataset and the targeted canonical pathway. The canonical pathways were also described with an activation
Table 2 Enriched canonical pathways of the differentially expressed genes using Ingenuity Pathway Analysis (IPA) software for insulin, high fat and high fat/insulin treatments

\begin{tabular}{|c|c|c|c|}
\hline & $-\log (p$-value) & Ratio & z-score \\
\hline \multicolumn{4}{|l|}{ Insulin } \\
\hline Calcium signaling & 7.98 & $2.12 \mathrm{E}-01$ & -0.426 \\
\hline p53 signaling & 5.00 & $2.16 \mathrm{E}-01$ & 0.218 \\
\hline Signaling by Rho Family GTPases & 4.72 & 1.63E-01 & 0.324 \\
\hline $\begin{array}{l}\text { Superpathway of inositol phos- } \\
\text { phate compounds }\end{array}$ & 4.62 & 1.67E-01 & 0.000 \\
\hline B cell receptor signaling & 4.56 & $1.76 \mathrm{E}-01$ & -1.095 \\
\hline \multicolumn{4}{|l|}{ High fat } \\
\hline Calcium signaling & 9.77 & 2.37E-01 & 0.557 \\
\hline Amyloid process & 5.52 & $3.20 \mathrm{E}-01$ & 0.000 \\
\hline B cell receptor signaling & 5.25 & 1.91E-01 & -0.690 \\
\hline $\begin{array}{l}\text { Role of NFAT in cardiac hyper- } \\
\text { trophy }\end{array}$ & 4.62 & $1.76 \mathrm{E}-01$ & -0.822 \\
\hline GNRH signalling & 4.60 & $1.91 \mathrm{E}-01$ & -1.633 \\
\hline Protein kinase A signalling & 4.28 & $1.48 \mathrm{E}-01$ & -1.342 \\
\hline PI3k signaling in B lymphocytes & 4.10 & $1.98 \mathrm{E}-01$ & -1.400 \\
\hline Type II diabetes mellitus signalling & 3.17 & $1.71 \mathrm{E}-01$ & 0.000 \\
\hline AMPK signaling & 2.15 & 1.40E-01 & -0.626 \\
\hline \multicolumn{4}{|l|}{ High fat insulin } \\
\hline RANK signaling in osteoclasts & 4.68 & $2.20 \mathrm{E}-01$ & -0.447 \\
\hline Antioxidant action of vitamin C & 3.92 & $2.02 \mathrm{E}-01$ & -1.886 \\
\hline IL-6 signaling & 3.86 & $1.88 \mathrm{E}-01$ & 0.000 \\
\hline April mediated signaling & 3.61 & $2.82 \mathrm{E}-01$ & -1.508 \\
\hline CD27 signaling in lymphocytes & 3.58 & 2.50E-01 & 0.000 \\
\hline NF-KB signaling & 3.42 & 1.63E-01 & -0.186 \\
\hline B Cell activating factor signaling & 3.40 & $2.68 \mathrm{E}-01$ & -1.265 \\
\hline Type I diabetes mellitus signaling & 3.30 & 1.87E-01 & -2.357 \\
\hline $\begin{array}{l}\text { Role of NFAT in cardiac hyper- } \\
\text { trophy }\end{array}$ & 3.29 & $1.53 \mathrm{E}-01$ & 2.121 \\
\hline IL-4 signaling & 3.18 & $1.98 \mathrm{E}-01$ & 0.000 \\
\hline
\end{tabular}

$\mathrm{z}$-score. The activation $\mathrm{z}$-score is an overall score that is used to infer an activation state for a given biological function. By comparing the observed differential regulation of a gene ("up" or "down") in the dataset to the known regulation direction associated with a specific canonical, the IPA software attributed a predicted activated $(Z$-score $\geq 2$ ) or an inhibited (Z-score $\leq-2)$ score to biological functions of our system. Enriched canonical pathways analysis essentially show that INS treatment is predicted to affect genes related to the calcium signaling with a slight tendency toward inhibition ( $\mathrm{z}$-score $=-0.426$ ) as well as genes involved in the $\mathrm{B}$ cell receptor signaling $(\mathrm{z}$-score $=-1.095)$. Similarly, HF treatment is predicted to negatively affect several major signaling pathways such as the protein kinase A signaling $(\mathrm{z}$-score $=-1.342)$, the PI3k signaling in $\mathrm{B}$ 
lymphocytes $(\mathrm{z}$-score $=-1.400)$ and to a lesser degree the AMPK signaling ( $\mathrm{z}$-score $=-0.626)$. Combination of both treatments principally affects antioxidant action of vitamin $C$, type I diabetes mellitus signaling and April mediated signaling but also genes predicted to have a positive impact on the NFAT signaling as demonstrated by the $\mathrm{z}$-score $(\mathrm{z}$-score $=2.121)$.

\section{Functional analysis}

The IPA Upstream Regulator analytic tool was also used to identify the main upstream regulators driving the observed gene expression changes in each treatment. The top 20 transcriptional regulators for the INS, HF and HFIns treatments are shown in Fig. 1. The overlap p-value was calculated with the Fisher's Exact Test and

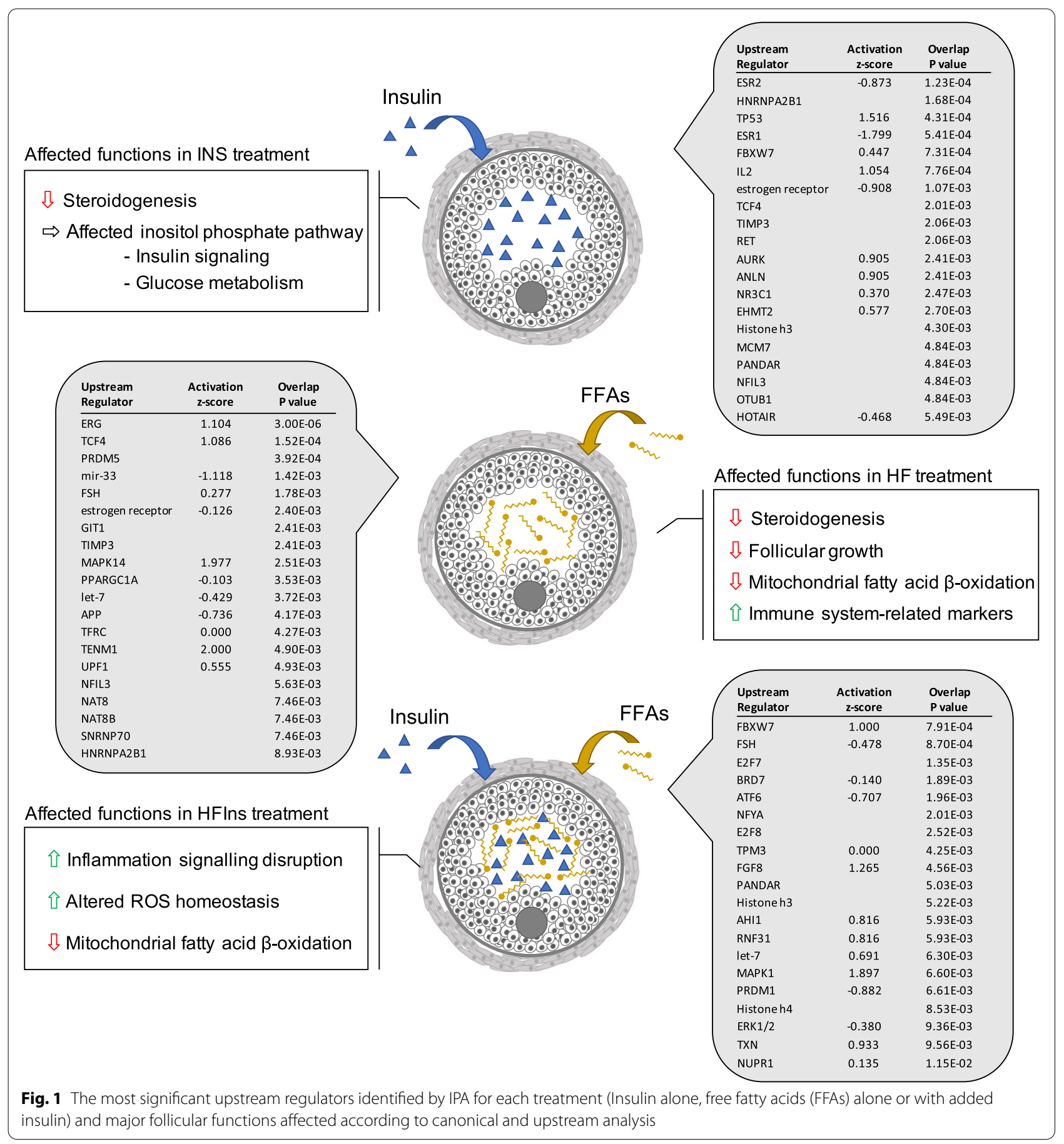


ranked the upstream regulators based on significant overlap between the gene in the dataset and the known gene targets of a given upstream regulator included in IPA's database. As for the canonical pathways, the $\mathrm{z}$-score inferred the activation of the transcriptional regulators by comparing the expression of genes in the dataset to what is expected from the literature. A complete list of all the significant upstream regulators for each treatment is available in supplemental data (Supplemental table S10-12). For further in-depth analysis of some canonical pathways, lists of downstream DEGs were uploaded to the PANTHER classification system for functional classification. Briefly, the PANTHER classification system employs the Gene Ontology (GO) and exploits a given list of genes to find functional classes and to provide curated associations of genes to biological pathways from the PANTHER Pathway resource [31].

For KGN cells exposed to insulin for $24 \mathrm{~h}$, IPA revealed upstream regulators related to cell proliferation, estrogen regulation, fatty acid metabolism, and glucose homeostasis. Also, among the most significant upstreams identified by the treatment, post-transcriptional factors linked to the regulation of insulin secretion and signaling pathways in insulin-sensitive cells were highlighted by the software. For KGN cells exposed to insulin, IPA identified a cell proliferation-related factor, the yes associated protein 1 (YAP1), as a significant and activated (z-score $=2,438, p$-value $=3,71 \mathrm{E}-02$ ) upstream regulator; while a chemoattractant for macrophages, the colony-stimulating factor 1 (CSF1) $(\mathrm{z}$-score $=-2,433, p$-value $=7,67 \mathrm{E}$ 03) was identified as an inhibited upstream regulating seven DEGs in our dataset (Supplemental Table 10). Among the significant upstream regulators identified, tumor protein P53 (TP53) $(\mathrm{z}$-score $=1,516, p$-value $=$ 4,31E-04), as well as POU class 5 homeobox 1 (POU5F1) $(\mathrm{z}$-score $=1,445, p$-value $=1,04 \mathrm{E}$-02) had a tendency toward activation. The peroxisome proliferator activated receptor gamma (PPARG) (z-score $=-1,451, p$-value $=3,79 \mathrm{E}-02)$ as well as the estrogen receptor 1 (ESR1) $(\mathrm{z}$-score $=-1,799, p$-value $=5,41 \mathrm{E}-04)$ tended toward inhibition according to the software cut-offs. Among the top significant upstream regulators identified by the software, many were related to glucose homeostasis such as F-box and WD repeat domain containing 7 (FBXW7, also known as $\mathrm{CDC} 4)$, nuclear receptor subfamily 3 group $\mathrm{C}$ member 1 (NR3C1), and nuclear factor interleukin 3 regulated (NFIL3) [32-34]. Others such as HOX transcript antisense RNA (HOTAIR) and euchromatic histone lysine methyltransferase 2 (EHMT2), which encodes for a ubiquitously expressed histone methyltransferase, were linked to the regulation of insulin secretion and signaling pathways in insulin-sensitive cells $[35,36]$.
Predicted regulator analysis of cells exposed to the high fat (HF) treatment suggested potential activation of several signaling pathways related to lipid metabolism, regulation of $\beta$-catenin signaling, and programmed cell death. Posttranscriptional factors known to play roles in fatty acid metabolism, insulin signaling, and granulosa cells programmed death were also identified in the upstream analysis for the HF treatment. The predicted regulator with the most significant p-value was the erythroblast transformation-specific transcription factor ERG (ERG) protein ( $p$-value $=3,79 \mathrm{E}-02$ ) encoded by a gene that was recently reported to be upregulated by androgen treatment, downregulated in atretic bovine medium follicles, and suggested as a potential target in polycystic ovary syndrome (PCOS) pathological changes in human granulosa cells [37, 38]. Among the top 10 most significant predicted upstream regulators, a conserved microRNA (miRNA) family, miR-33, which plays a role in fatty acid metabolism and insulin signaling [39] was identified $(\mathrm{z}$-score $=-1,118, p$-value $=1,43 \mathrm{E}-03)$. Let-7, another miRNA family acting at the posttranscriptional level and involved in granulosa cell programmed death was also identified in HF treatment ( $\mathrm{z}$-score $=-0,429, p$-value $=$ 3,72E-03). The PPARG coactivator 1 alpha (PPARGC1A) gene $(\mathrm{z}$-score $=-0,103, p$-value $=3,53 \mathrm{E}$-03) was identified as well and is another candidate gene involved in follicular atresia and in the regulation of genes involved in energy metabolism [40, 41]. A key effector of stress signals in cells, the mitogen-activated protein kinase 14 (MAPK14), was also identified by IPA as a predicted regulator with a strong tendency toward activation in the HF treatment $(\mathrm{z}$-score $=1,977, p$-value $=2,51 \mathrm{E}$-03).

Finally, upstream regulator analysis of KGN cells exposed to the combined high fat and insulin (HFIns) treatment revealed predicted regulators related to cell cycle progression, glucose homeostasis, as well as steroidogenesis signaling and regulation of cellular oxidative status. Two factors potentially involved in glucose homeostasis, F-box and WD repeat domain containing 7 (FBXW7) and bromodomain-containing protein 7 (BRD7), were influenced by the HFIns treatment [34, 42]. FBXW7, the most significant upstream regulator in this treatment, was also among the top five most significant upstream for the insulin treatment. The miRNA let-7, which was identified in the HF treatment, was also influenced by the HFIns treatment. Other important factors involved in the cell cycle progression such as E2F transcription factor 7 (E2F7) and E2F transcription factor 8 (E2F8) were highlighted by the upstream analysis. The HFIns treatment is suggested to have affected FSH signaling as well as steroidogenesis regulation since several factors such as fibroblast growth factor 8 (FGF8), mitogen-activated protein kinase 1 (MAPK1), and the 
extracellular signal-regulated kinase 1/2 (ERK1/2), which are involved in estradiol signaling, were identified among the most significant predicted regulators. The thioredoxin (TXN) gene, a regulator of cellular redox status, was also highlighted as a significant predicted regulator in the HFIns treatment with a $\mathrm{z}$-score of almost one (z-score $=0,933, p$-value $=9,56 \mathrm{E}-03)$.

\section{Discussion}

Obese women have decreased fertility, with decreased numbers and quality of oocytes and embryos. Although the biology and mechanisms are still poorly understood, there is rising evidence that metabolic disturbances in obese women affect reproductive functions [1, 2, 43, 44]. Among the metabolites found in follicular fluid and closely affecting follicular and oocyte development, free fatty acids were identified as key molecules contributing to the obesity-associated impaired oocyte developmental competence and metabolism [15]. Along with the increase in fatty acid concentrations, insulin levels were also increased in women afflicted with metabolic $[15,18$, $45,46]$. The results presented here revealed the direct sensitivity of granulosa cells to the metabolic context of the female in a dominant-like follicular stage. Using a unique in vitro human cell model that allows the study of gene signaling in a more stable context when compared to human granulosa cells obtained from in vitro fertilization patients, we were able to characterize the major biological functions and pathways likely to be affected by an increase in free fatty acids and insulin in the surrounding cellular environment. Results revealed the granulosa cell response and the mechanisms triggered when facing a metabolic challenge such as an increase in fatty acid concentration which is one of the main consequences of obesity in women. The analysis of the transcriptomic response highlights numerous genes and pathways related to steroidogenesis, mitochondrial and energy metabolism as well as oxidative stress and inflammationrelated hub genes and canonical pathways. Results also support the fact that a combination of high fat and high insulin may be worse than high fat alone, as not only the apoptotic signature increased but cytokines associated with inflammation and oxidative stress-related pathways were also higher in the combination treatment.

\section{Mitochondrial and energy metabolism}

Transcriptomic analysis with the IPA software revealed that granulosa cell exposure to high concentrations of free fatty acids affected major canonical pathways related to mitochondrial function and energy metabolism such as calcium signaling, the phosphatidylinositol 3-kinases/ protein kinase B (PI3K/AKT) signaling, and the 5' AMPactivated protein kinase (AMPK) signaling. Calcium signaling was identified as the top disrupted canonical pathway in response to the HF treatment. In granulosa cells, calcium homeostasis was shown to be influenced by both FSH and LH, and to mediate mitochondrial biogenesis in differentiated human granulosa cells by regulating several factors involved in mitochondrial DNA (mtDNA) transcription and replication [47, 48]. Mainly studied in liver and in pancreatic tissues, calcium signaling disruption related to nutrient stress, or metabolic conditions such as obesity, was suggested to impair the endoplasmic reticulum (ER) and mitochondria integrity and functions as reviewed by Arruda et al., 2015. Saturated fatty acid incorporation in the ER membrane affected membrane fluidity and the function of $\mathrm{Ca}^{2+}$ linked receptors [4954]. Intracellular $\mathrm{Ca}^{2+}$-dependent signaling molecules are involved in the regulation of cellular metabolism as many proteins and enzymes participate in fatty acid metabolism, tricarboxylic acid cycles, as well as apoptosis [55, 56]. Disruption of intracellular calcium homeostasis was directly related to the pathogenesis of insulin insensitivity in liver [57]. Tending towards inhibition in response to the insulin treatment, and activation in response to the HF treatment, such a $\mathrm{Ca}^{2+}$-related mechanism might be critical in the onset of impaired granulosa cell function resulting from metabolic challenges especially in type 2 diabetes (T2D) patients.

Along with the other canonical pathways affected by the HF treatment, the protein kinase A (PKA) and PI3K signaling were also identified as impaired with a tendency towards inhibition. Insulin action in human granulosa cells, including glucose uptake, was shown to be mediated via the insulin receptor substrate 1 (IRS1) protein and PI3K/AKT signaling pathways $[25,58,59]$. Accumulation of fatty acid metabolites such as dyacylglycerides (DAG) and ceramides was suggested to affect key factors of the PI3K signaling, to inhibit insulin signaling, and to induce endoplasmic reticulum (ER) and oxidative stress [60, 61]. In our results, the negative effect on the PI3K signaling pathway may indicate that fatty acids are involved in the induction of insulin resistance by interfering with this pathway in human granulosa cells as observed in a previous study on human and mouse granulosa cells [22]. Moreover, disruption of PKA and AKT signaling pathways affected many granulosa cell key functions such as steroidogenesis and growth and differentiation [62]. The actions of both gonadotrophins, FSH and LH, are mediated via PKA and AKT signaling. PKA is a master kinase for granulosa cell differentiation and proliferation while AKT acts as a permissive pathway for PKA signaling and regulates cell survival [27, 63-65]. Consistent with our results, obesity in women was associated with lower levels of estradiol $[46,66]$. In a recent study, $\mathrm{Xu}$ et al., 2019 also showed decreased estradiol (E2) production in 
women with elevated BMI along with a reduced response to FSH stimulation exacerbated in the presence of high insulin concentrations [24]. Furthermore, AKT targets many metabolism-related factors such as FOXO1 and peroxisome proliferator-activated receptor coactivator $1 \alpha$ $(\mathrm{PGC} 1 \alpha)$ which regulate gene expression to increase gluconeogenesis and fatty acid oxidation [67]. The PPARG coactivator 1 alpha $(P P A R G C 1 A)$ gene $(\mathrm{z}$-score $=-0,103$, $\mathrm{p}$-value $=3,53 \mathrm{E}-03)$ encoding for the $\mathrm{PGC1} \alpha$ protein was identified in our study and was previously suggested to be involved in follicular atresia as well as steroidogenesis regulation and progesterone production in granulosa cells $[41,68,69]$. Slightly inhibited as a predicted regulator in the HF treatment, this gene was significantly upregulated in the insulin treatment and inhibited in the HFIns treatment. The transcriptional coactivator protein PGC- $1 \alpha$, which is stimulated through calcium signaling, insulin, and p38 MAPK action, was described as a master regulator of mitochondrial biogenesis and function, and is thought to act as a key factor regulating multiple metabolic pathways such as gluconeogenesis and fatty acid synthesis and oxidation, or glycolysis [70]. As reviewed by Cheng et al. 2018, PGC- $1 \alpha$ binds to target genes that influence mitochondrial metabolism and impact fatty acid utilization and transport. In our HF treatment, IPA analysis suggested PPARGC1A regulation of Carnitine Palmitoyltransferase 1B (CPT1B), glycerol kinase (GK), and cluster of differentiation 36 (CD36), all DEGs related to FA uptake, triglyceride metabolism, and fatty acid oxidation (FAO) [71-74]. Closely related to PPARGC1A action, another energy sensor and energy homeostasis regulator sensitive to the AMP:ATP ratio was identified by our study as being negatively affected in granulosa cells exposed to fatty acids [75]. The AMP-activated protein kinase (AMPK) is a well-known regulator of enzymes involved in the synthesis of fatty acids, cholesterol, and glycogen [76]. It is involved in the pathogenesis of insulin-resistant states and is targeted by metformin, an insulin sensitizer, for the treatment of type 2 diabetes. The alteration of AMPK activity in stress conditions such as obesity can lead to dysregulated metabolism and insulin resistance [77-79]. Consistent with our results, and as reviewed by Lyons and Roche, 2018, obesity was associated with reduced AMPK activation and reduced fatty acid oxidation [80, 81]. Several studies investigated the role of AMPK in granulosa cells and the results were summarized by Bertoldo et al., 2014 [82-85]. In bovine and human granulosa cells, AMPK activation by metformin reduced estradiol and progesterone production as well as steroidogenesis-related proteins $[85,86]$. The AMPK enzyme regulates a wide array of physiological and cellular events and seems to have diverse functions in granulosa cells which evolve during folliculogenesis.
Our results reinforced its role as a key molecule involved in human granulosa cell sensitivity to the metabolic context [82].

In agreement with the literature and the results mentioned above, the mitogen-activated protein kinase 14 (MAPK14), also called p38- $\alpha$, was also identified as a significant predicted regulator with a strong tendency toward activation in the HF treatment. The $\mathrm{p} 38$ protein is a key effector activated by stress signals and oxidative stress and is involved in inflammation and apoptosis processes. In granulosa cells, along with its suggested role in the pro-apoptosis/pro-survival balance, p38 was also reported to be involved in steroidogenesis regulation by stimulating estradiol production and reducing progesterone production [87-90]. The $\mathrm{p} 38$ protein was also directly activated by saturated fatty acids in human pancreatic $\beta$-cells and was linked to energy metabolism in several tissues, regulating gluconeogenesis among other processes $[87,91]$. This factor plays a key role in FFAinduced transcription of gluconeogenic genes including PPARGC1A, and was highlighted as a key molecule in the response of bovine granulosa cells to the mother nutrition and metabolic stress status thereby influencing fertility outcomes [92-94]. Among the downstream effectors of MAPK14 affected by treatment was the vitamin D receptor (VDR) which was upregulated (DEG) in the insulin and HF treatments but downregulated in the combination treatment (HFIns). Although the pathogenetic mechanisms linking obesity, vitamin $\mathrm{D}$, and fertility are still not understood, vitamin D deficiency was previously associated with female infertility [95]. Additionally, the VDR was suggested to be involved in the regulation of genes involved in glucose and lipid metabolism [96]. Accumulating evidence from human studies, reviewed by Anagnostis et al. in 2013, suggested a key role of vitamin $\mathrm{D}$ deficiency in metabolic disturbances including insulin resistance in polycystic ovary syndrome (PCOS) in obese women [97, 98]. The expression of the VDR gene was downregulated in PCOS and in obese women when compared to non-PCOS and non-obese women [99]. Besides playing a role in energy metabolism, the VDR is also involved in steroidogenic functions in human ovarian and granulosa cells [100-102].

Taken together, the results showed that when exposed to high concentrations of fatty acids, granulosa cells exhibited a certain sensitivity through modulations of numerous genes and pathways related to mitochondrial biofunctions, energy metabolism, and steroidogenesis. Analysis of major canonical pathways and upstream regulators suggested an impaired steroidogenesis, a predicted reduced response to gonadotrophin and insulin levels, and a dysregulated fatty acid-related metabolism mostly involving the PI3K/AKT signaling. Overall, although 
the results of this study provided a limited insight into the onset response of human granulosa cells, this study allowed us to identify potential new pathways and targets worth considering for further research.

\section{Inflammation and oxidative stress}

As a consequence of ER and mitochondrial stress, FFA were suggested to induce a lipotoxic response and to increase levels of reactive oxygen species (ROS) [103]. Persistent cell damage and chronic low-grade inflammation are the hallmarks of reproductive tissues exposed to FFA, and follicles from obese women presented inflammation characteristics [18, 104]. Consistently, results from this study identified the nuclear factor of activated T-cells (NFAT) signaling pathway with a tendency toward inhibition among the top 10 canonical pathways affected by the HF treatment. The NFAT family members, studied mostly in $\mathrm{T}$ and $\mathrm{B}$ cells, participated in transcriptional induction of various immune response genes as well as cytokine gene expression $[105,106]$. Thought to be key transcription factors for immune cell activation and differentiation, NFAT family members were also suggested to be involved in adipocyte differentiation, modulation of adipokine gene expression, and to participate in glucose and insulin homeostasis [105, 107-109]. Although NFATC1 was upregulated following stimulation of porcine granulosa cells with a phospholipase C (PLC) activator [110], the actions mediated by the NFAT family in granulosa cells still remain poorly understood. Functional classification of the 38 downstream effector genes of the NFAT canonical pathway using PANTHER Classification systems showed that the differentially expressed genes were, among others, related to inflammation mediated by chemokine and cytokine signaling pathways, and to the $5 \mathrm{HT} 2$ type receptor or serotonin receptor (5-HT2A) signaling pathway which is known to stimulate an increase in intracellular $\mathrm{Ca}^{2+}$ levels via the PLC/IP3/ DAG pathway [111]. This canonical pathway tended to be inhibited in the HF and insulin treatments, but activated in the HFIns treatment $(\mathrm{z}$-score $=2.212)$ suggesting that high fat in combination with a high insulin concentration could be a key signal for the onset of inflammatory and immune processes in human granulosa cells [112-114]. As reviewed by Duffy et al., (2019), women with PCOS, which is often associated with obesity and high insulin levels, had altered inflammatory transcriptome in granulosa cells as some inflammatory genes were overexpressed, along with genes responsible for leukocyte migration [113, 115-118]. Obesity in combination with PCOS seemed to enhance inflammatory gene expression as overweight PCOS women exhibited the most differences in gene expression profiles among the contrasts studied [115]. Consistent with this understanding of the results, analysis of the HFIns treatment highlighted interkeulin 6 (IL-6) among the top 3 canonical pathways and interleukin 4 (IL-4) as being involved in granulosa cell response to such metabolic challenge. Interleukin 4 is an anti-inflammatory cytokine and Il-6 is a proinflammatory pleiotropic cytokine secreted by granulosa cells [119, 120]. Modulated by known pro-inflammatory cytokines such as interleukin-1a (IL1A), IL6 was suggested to contribute to the ovulatory process and to be involved in bidirectional communication between the ovary and cellular components of the immune system [121]. It also increased in ovaries from obese women and mice and may participate in the chronic low-grade inflammation associated with the PCOS pathogenesis [115, 122-124].

Regarding the oxidative stress that is often increased in obesity and associated metabolic diseases, the thioredoxin (TXN) gene, which encodes the TXR protein a ubiquitously expressed small protein playing a key role in regulating the cellular redox status, was highlighted as a predicted regulator with a tendency towards activation in the HFIns treatment [125]. Longchain saturated fatty acids were associated with the generation of proapoptotic molecules and the accumulation of intracellular ROS thereby inducing the dysregulation of mitochondrial function and resulting in lipotoxicity [103]. Maternal obesity during the periconceptional period disrupted mitochondrial homeostasis and increased the levels of ROS in mouse oocytes and zygotes [126]. Moreover, obese women had higher follicular fluid oxidative stress markers [127]. Thioredoxin, a component of the TRX/TRXR system induced by oxidative stress-generating stimuli and involved in antioxidant defense mechanisms, was present throughout follicular development in women and was also identified in follicular fluid $[125,128,129]$. The predicted activation of the thioredoxin pathway following treatment with both insulin and high fat could suggest an enhanced oxidative environment compared to high fat exposure alone or insulin alone. In line with this, the antioxidant action of vitamin $\mathrm{C}$ was identified as the third most significant canonical pathway in the HFIns treatment. Vitamin C (L-ascorbic acid) protects against oxidative stress and cellular damage induced by ROS [130]. In mice, vitamin $C$ exerted beneficial effects against ovarian aging due in part to its antioxidant capacity [131]. Moreover, previous studies reported that this hormonally regulated vitamin played a key role in preventing atresia and apoptosis in granulosa cells and dominant follicles [132,133]. The tendency toward inhibition of this pathway could suggest a disturbed equilibrium of pro-oxidant and antioxidant molecules in human granulosa cells exposed to a combination of high insulin and high fat. 
Finally, a noteworthy effect of the high concentrations of FFA and insulin (HFIns) was the strong involvement of the tumor necrosis factor (TNF) superfamily and the nuclear factor-kappa B (NF-kB) family in the granulosa cell response as almost all the top canonicals were directly or indirectly related to those two signaling pathways. Among the top 10 most significant pathways affected by this treatment was the RANK signaling in Osteoblasts. The RANK protein, encoded by TNFRSF11A, also known as receptor activator of NF-KB (RANK), is a key molecule that regulates the differentiation and function of osteoclasts. As reviewed by Park et al. (2007), RANK signaling can lead to the activation of several mitogenactivated protein kinases (MAPKs) as well as the transcription factor nuclear factor-kB (NF-kB) [134]. Among the DEGs suggested as being part of this canonical pathway, many MAP kinases were included as well as NF-kB signaling pathway-related genes (MAPK14, NFKB Inhibitor Delta (NFKBID), inhibitor of nuclear factor kappa $B$ kinase subunit beta (IKBKB), inhibitor of nuclear factor kappa B kinase regulatory subunit gamma (IKBKG), nuclear factor NF-kappa-B p65 subunit (RELA), etc...). The nuclear factor - kappa B (NF-kB) family is a group of transcription factors involved in many well-recognized cell functions including regulation of inflammatory response, cell survival/cell apoptosis, maturation of the immune system, and cell differentiation [135-137]. In bovine and porcine granulosa cells, NF- $\mathrm{KB}$ activity was linked to estradiol-mediated signaling pathway, progesterone production, as well as GC survival/apoptosis, with some discrepancies regarding its role in apoptosis among the different species [138-143]. Reinforcing the idea of a strong involvement of this pathway in response to the HFIns treatment, canonical analysis highlighted a treatment-related disruption of the APRIL signaling pathway, also known as TNFS13A, as well as the CD27 signaling pathway, also known as the tumor necrosis factor receptor superfamily 7 (TNFRSF7). Besides being regulated by RANK signaling, NF- $\mathrm{KB}$ family members are also regulated by many other cytokines of the TNF superfamily that stimulate various cell type- and pathway-specific responses [144]. The APRIL signaling, which was suggested to mediate a pro-survival response in cells and to act through the activation of the NF- $\mathrm{kB}$ pathway tended to be inhibited by the fatty acid and insulin combined treatment [145-148]. The CD27 protein, which is also related to the activation of the NF- $\mathrm{kB}$ signaling, was likewise identified as a top pathway due to its relation to the NF- $\mathrm{BB}$ family [149]. All connected together, inflammation-related factors such as TNFa, IL6, NOS2, and the transcription factor p65, also known as nuclear factor NF-kappa-B p65 subunit (RELA), were all increased in the ovarian tissue of obese mice $[123,150]$. Interestingly, factors like NOS2 and RELA were inhibited in the HFIns treatment; and although the canonical pathway for NF- $\mathrm{kB}$ was neither activated nor inhibited in the HFIns treatment, our results still suggest that this pathway is influenced by treatment and could therefore be involved in the mechanisms through which human granulosa cells respond to metabolic challenges. Globally, when exposed to metabolic challenges such as high concentrations of fat and insulin, human granulosa cells seemed to activate a gene expression program linked to the immune response and to inflammatory processes. Although after only $24 \mathrm{~h}$ of exposition, the whole mechanism might not be fully engaged yet, the results demonstrated a certain sensitivity of the different signaling pathways previously mentioned. In agreement with the specific genomic signatures found in this study, inflammation and oxidative stress are two processes tightly linked with one another and this interdependence is a known contributing factor to the development of metabolic diseases.

Overall, this study provided, for the first time, a more comprehensive profile of gene expression in human granulosa cells exposed to metabolic challenge contexts of high-fat and/or high insulin levels. The results of our study suggested that human granulosa cells are sensitive to specific FFAs and to insulin in their environment. When exposed to such challenges, important changes and gene profile remodeling occur in relation to the energy and mitochondrial metabolism, homeostasis, as well as to key functions such as steroidogenesis for which the signaling pathways were markedly affected by our high fat treatment. Moreover, when high insulin levels were added to high fat concentrations, increased oxidative stress and inflammation related reactions were observed suggesting that the combination of both conditions might affect further follicular development in a more critical way. Even though we are aware that in vitro and in vivo contexts differ, as many other adipokines and molecules can be found in follicular fluid and are surely affecting human granulosa cells responses, this study still provided a great overall picture of the mechanisms taking part in this response. Cultured KGN cells have been found to bear functional FSH receptors and to be unresponsive to hCG stimulation suggesting a developmental stage close to antral/ undifferentiated follicle [26]. Despite the fact that KGN cells do not differentiate in a typical pre-ovulatory stage which limits the developmental window under investigation, they represent a unique model for the study of antral/dominant follicular phase. Because of the own nature of KGN cells which are derived from a stage-3 diagnosed granulosa cell tumor further research and validation in native granulosa cells for each pathway put forward by our analysis will be needed [26, 151]. 
Nevertheless, with all the conserved characteristics of native granulosa cell including cAMP-inducible aromatase expression, it is believed that KGN cell line is a readily accessible system for characterizing signalling pathways in human folliculogenesis using mechanistic experiments [26]. Finally, even though high-throughput sequencing methods and software such as IPA are powerful tools for building gene correlation networks, biological interpretation of the massive amount of data generated remains a challenge. This study demonstrated that human granulosa cells can adjust to the maternal metabolism; and although this overall picture might not be exhaustive, this is a first step in the unravelling of the mechanisms involved.

\section{Supplementary Information}

The online version contains supplementary material available at https://doi. org/10.1186/s13048-021-00934-6.

Additional file 1: Supplemental Table S1. List of the first 100 upregulated DEGs in High fat + insulin (HFIns) treatment. Supplemental Table S2. List of the first 100 downregulated DEGs in High fat + insulin (HFIns) treatment. Supplemental Table S3. List of the first 100 upregulated DEGs in High fat (HF) treatment. Supplemental Table S4. List of the first 100 downregulated DEGs in High fat (HF) treatment. Supplemental Table S5. List of the first 100 upregulated DEGs in Insulin (INS) treatment. Supplemental Table S6. List of the first 100 downregulated DEGs in Insulin (INS) treatment. Supplemental Table S7. Complete list of significant ( $p$-value $\leq 0,05)$ enriched canonical pathways of the differentially expressed genes using Ingenuity Pathway Analysis (IPA) software for insulin (INS) treatment. Supplemental Table S8. Complete list of significant $(p$-value $\leq 0,05)$ enriched canonical pathways of the differentially expressed genes using Ingenuity Pathway Analysis (IPA) software for high fat (HF) treatment. Supplemental Table S9. Complete list of significant ( $p$-value $\leq 0,05$ ) enriched canonical pathways of the differentially expressed genes using Ingenuity Pathway Analysis (IPA) software for high fat + insulin (HFIns) treatment. Supplemental Table S10. List of most significant upstream regulators in Insulin (INS) treatment ( $p$-value of overlap $\leq 0,05$ ). Supplemental Table S11. List of most significant upstream regulators in High fat (HF) treatment ( $p$-value of overlap $\leq 0,05$ ). Supplemental Table S12. List of most significant upstream regulators in High fat + insulin (HFIns) treatment ( $p$-value of overlap $\leq 0,05$ ).

\section{Acknowledgements}

The authors thank Éric Fournier who carried out the statistical analysis of the RNAseq data. Special thanks to Dr. Jean-Patrice Baillargeon who provided valuable advice on the experimental design considering his great expertise on the subject. Lastly, we'd like to thank Sylvie Bilodeau-Goeseels for proofreading and for improving the use of English in the manuscript.

\section{Authors' contributions}

P.G.T carried out the experiment and wrote the manuscript. Both C.F and M-A.S. contributed to the final version of the manuscript by providing critical feedback and helped shape the analysis and manuscript. M-A.S. supervised the project. The author(s) read and approved the final manuscript.

\section{Funding}

Financial support for this study was received from the Natural Sciences and Engineering Research Council of Canada (NSERC).

The data discussed in this publication have been deposited in NCBI's Gene Expression Omnibus and are accessible through GEO Series accession number GSE161914.

\section{Availability of data and materials}

The data discussed in this publication have been deposited in NCBI's Gene Expression Omnibus and are accessible through GEO Series accession number GSE161914.

\section{Declarations}

\section{Ethics approval and consent to participate}

According to the Human Research Ethics Committee of Laval University (CÉRUL), a research ethics board (REB) review was not required to work with the KGN cell line.

\section{Consent for publication}

Not applicable.

\section{Competing interests}

The authors declare that they have no competing interests.

Received: 9 September 2021 Accepted: 8 December 2021

Published online: 20 December 2021

\section{References}

1. Fontana R, Della Torre S. The deep correlation between energy metabolism and reproduction: a view on the effects of nutrition for women fertility. Nutrients [Internet]. 2016 [cited 2020 Oct 27]; 8. Available from: https://www.ncbi.nlm.nih.gov/pmc/articles/PMC4772050/.

2. Andreas E, Winstanley YE, Robker RL. Effect of obesity on the ovarian follicular environment and developmental competence of the oocyte. Curr Opin Endocr Metab Res. 2021;18:152-8.

3. Desmet KLJ, Van Hoeck V, Gagné D, Fournier E, Thakur A, O'Doherty AM, et al. Exposure of bovine oocytes and embryos to elevated non-esterified fatty acid concentrations: integration of epigenetic and transcriptomic signatures in resultant blastocysts. BMC Genomics. 2016;17:1004

4. Hoeck W, Leroy JLMR, Alvarez MA, Rizos D, Gutierrez-Adan A, Schnorbusch K, et al. Oocyte developmental failure in response to elevated nonesterified fatty acid concentrations: mechanistic insights. Reproduction. 2013;145:33-44.

5. Jungheim ES, Macones GA, Odem RR, Patterson BW, Lanzendorf SE, Ratts VS, et al. Associations between free fatty acids, cumulus oocyte complex morphology and ovarian function during in vitro fertilization. Fertil Steril. 2011;95:1970-4.

6. Leroy JLMR, Vanholder T, Mateusen B, Christophe A, Opsomer G, de Kruif $A$, et al. Non-esterified fatty acids in follicular fluid of dairy cows and their effect on developmental capacity of bovine oocytes in vitro. Reproduction. 2005;130:485-95.

7. Mu YM, Yanase T, Nishi Y, Tanaka A, Saito M, Jin CH, et al. Saturated FFAs, palmitic acid and stearic acid, induce apoptosis in human granulosa cells. Endocrinology. 2001;142:3590-7.

8. Sharma A, Baddela VS, Becker F, Dannenberger D, Viergutz T, Vanselow J. Elevated free fatty acids affect bovine granulosa cell function: a molecular cue for compromised reproduction during negative energy balance. Endocr Connect. 2019;8:493-505.

9. Valckx SDM, De Pauw I, De Neubourg D, Inion I, Berth M, Fransen E, et al BMI-related metabolic composition of the follicular fluid of women undergoing assisted reproductive treatment and the consequences for oocyte and embryo quality. Hum Reprod Oxf Engl. 2012;27:3531-9.

10. Van Hoeck V, Sturmey RG, Bermejo-Alvarez P, Rizos D, Gutierrez-Adan A, Leese $\mathrm{HJ}$, et al. Elevated non-esterified fatty acid concentrations during bovine oocyte maturation compromise early embryo physiology. PLoS ONE 2011 [cited 2016 Dec 3];6. Available from: http://www.ncbi.nlm. nih.gov/pmc/articles/PMC3157355/.

11. Yang X, Wu LL, Chura LR, Liang X, Lane M, Norman RJ, et al. Exposure to lipid-rich follicular fluid is associated with endoplasmic reticulum stress and impaired oocyte maturation in cumulus-oocyte complexes. Fertil Steril. 2012;97:1438-43. 
12. Dunning KR, Russell DL, Robker RL. Lipids and oocyte developmental competence: the role of fatty acids and $\beta$-oxidation. Reproduction. 2014;148:R15-27.

13. Papackova Z, Cahova M. Fatty acid signaling: the new function of intracellular lipases. Int J Mol Sci. 2015;16:3831-55.

14. Jorritsma R, César ML, Hermans JT, Kruitwagen CLJJ, Vos PLAM, Kruip TAM. Effects of non-esterified fatty acids on bovine granulosa cells and developmental potential of oocytes in vitro. Anim Reprod Sci. 2004:81:225-35.

15. Valckx SD, Arias-Alvarez M, De Pauw I, Fievez V, Vlaeminck B, Fransen E, et al. Fatty acid composition of the follicular fluid of normal weight, overweight and obese women undergoing assisted reproductive treatment: a descriptive cross-sectional study. Reprod Biol Endocrinol. 2014;12:13.

16. Jungheim ES, Travieso JL, Carson KR, Moley KH. Obesity and reproductive function. Obstet Gynecol Clin North Am. 2012;39:479-93.

17. Leroy JLMR, Vanholder T, Delanghe JR, Opsomer G, Van Soom A, Bols PEJ, et al. Metabolite and ionic composition of follicular fluid from different-sized follicles and their relationship to serum concentrations in dairy cows. Anim Reprod Sci. 2004;80:201-11.

18. Robker RL, Akison LK, Bennett BD, Thrupp PN, Chura LR, Russell DL, et al. Obese women exhibit differences in ovarian metabolites, hormones, and gene expression compared with moderate-weight women. J Clin Endocrinol Metab. 2009:94:1533-40.

19. Aardema H, Vos PLAM, Lolicato F, Roelen BAJ, Knijn HM, Vaandrager AB, et al. Oleic acid prevents detrimental effects of saturated fatty acids on bovine oocyte developmental competence. Biol Reprod. 2011;85:62-9.

20. Van Hoeck V, Rizos D, Gutierrez-Adan A, Pintelon I, Jorssen E, Dufort I, et al. Interaction between differential gene expression profile and phenotype in bovine blastocysts originating from oocytes exposed to elevated non-esterified fatty acid concentrations. Reprod Fertil Dev. 2015;27:372-84

21. Sakumoto T, Tokunaga Y, Tanaka H, Nohara M, Motegi E, Shinkawa T, et al. Insulin resistance/hyperinsulinemia and reproductive disorders in infertile women. Reprod Med Biol. 2010;9:185-90.

22. Xu L, Wang W, Zhang X, Ke H, Qin Y, You L, et al. Palmitic acid causes insulin resistance in granulosa cells via activation of JNK. J Mol Endocrinol. 2019:62:197-206.

23. Purcell SH, Moley KH. The impact of obesity on egg quality. J Assist Reprod Genet. 2011;28:517-24.

24. Xu P, Huang B-Y, Zhan J-H, Liu M-T, Fu Y, Su Y-Q, et al. Insulin reduces reaction of follicular granulosa cells to $\mathrm{FSH}$ stimulation in women with obesity-related infertility during IVF. J Clin Endocrinol Metab. 2019;104:2547-60.

25. Diamanti-Kandarakis E, Chatzigeorgiou A, Papageorgiou E, Koundouras D, Koutsilieris M. Advanced glycation end-products and insulin signaling in granulosa cells. Exp Biol Med. 2016;241:1438-45.

26. Nishi Y, Yanase T, Mu Y, Oba K, Ichino I, Saito M, et al. Establishment and characterization of a steroidogenic human granulosa-like tumor cell line, KGN, that expresses functional follicle-stimulating hormone receptor. Endocrinology. 2001;142:437-45.

27. Tremblay PG, Sirard M-A. Gene analysis of major signaling pathways regulated by gonadotropins in human ovarian granulosa tumor cells (KGN)+. Biol Reprod. 2020;103:583-98.

28. Bolger AM, Lohse M, Usadel B. Trimmomatic: a flexible trimmer for Illumina sequence data. Bioinforma Oxf Engl. 2014;30:2114-20.

29. Bray NL, Pimentel H, Melsted P, Pachter L. Near-optimal probabilistic RNA-seq quantification. Nat Biotechnol. 2016;34:525-7.

30. McCarthy DJ, Chen Y, Smyth GK. Differential expression analysis of multifactor RNA-Seq experiments with respect to biological variation. Nucleic Acids Res. 2012;40:4288-97.

31. Mi H, Huang X, Muruganujan A, Tang H, Mills C, Kang D, et al. PANTHER version 11: expanded annotation data from Gene Ontology and Reactome pathways, and data analysis tool enhancements. Nucleic Acids Res. 2017;45:D183-9.

32. Bauerle KT. Harris C. Glucocorticoids and diabetes. Mo Med. 2016;113:378-83

33. Kang G, Han H-S, Koo S-H. NFIL3 is a negative regulator of hepatic gluconeogenesis. Metabolism. 2017;77:13-22.
34. Zhao J, Xiong X, Li Y, Liu X, Wang T, Zhang H, et al. Hepatic F-box protein FBXW7 maintains glucose homeostasis through degradation of fetuinA. Diabetes. 2018:67:818-30.

35. Xue W, Huang J, Chen H, Zhang Y, Zhu X, Li J, et al. Histone methyltransferase G9a modulates hepatic insulin signaling via regulating HMGA1. Biochim Biophys Acta Mol Basis Dis. 2018;1864:338-46.

36. Li M, Guo Y, Wang X-J, Duan B-H, Li L. HOTAIR participates in hepatic insulin resistance via regulating SIRT1. Eur Rev Med Pharmacol Sci. 2018:22:7883-90.

37. Douville G, Sirard M-A. Changes in granulosa cells gene expression associated with growth, plateau and atretic phases in medium bovine follicles. J Ovarian Res. 2014;7:50.

38. Song J, Diao F, Ma X, Xu S, Cui Y, Jiang S, et al. Androgen upregulates NR4A1 via the TFAP2A and ETS signaling networks. Int J Biochem Cell Biol. 2019;113:1-7.

39. Dávalos A, Goedeke L, Smibert P, Ramírez CM, Warrier NP, Andreo U, et al. miR-33a/b contribute to the regulation of fatty acid metabolism and insulin signaling. Proc Natl Acad Sci U S A. 2011:108:9232-7.

40. Cao R, Wu WJ, Zhou XL, Xiao P, Wang Y, Liu HL. Expression and preliminary functional profiling of the let-7 family during porcine ovary follicle atresia. Mol Cells. 2015;38:304-11.

41. Zhang G, Wan Y, Zhang Y, Lan S, Jia R, Wang Z, et al. Expression of mitochondria-associated genes (PPARGC1A, NRF-1, BCL-2 and BAX) in follicular development and atresia of goat ovaries. Reprod Domest Anim Zuchthyg. 2015;50:465-73.

42. Park SW, Herrema H, Salazar M, Cakir I, Cabi S, Basibuyuk Sahin F, et al. BRD7 regulates XBP1s'activity and glucose homeostasis through its interaction with the regulatory subunits of PI3K. Cell Metab. 2014:20:73-84.

43. Kini S, Ramalingam MA. Mahmood T. Obesity and female infertility. Obes Gynecol. Elsevier; 2020 [cited 2021 Nov 23]. p. 83-90. Available from: https://linkinghub.elsevier.com/retrieve/pii/B97801281791920 00097.

44. Talmor A, Dunphy B. Female obesity and infertility. Best Pract Res Clin Obstet Gynaecol. 2015;29:498-506.

45. Pasquali R. Obesity, fat distribution and infertility. Maturitas. 2006;54:363-71.

46. Jungheim ES, Lanzendorf SE, Odem RR, Moley KH, Chang AS, Ratts VS, Morbid obesity is associated with lower clinical pregnancy rates after in vitro fertilization in women with polycystic ovary syndrome. Fertil Steril. 2009;92:256-61.

47. Egbert JR, Fahey PG, Reimer J, Owen CM, Evsikov AV, Nikolaev VO, et al. Follicle-stimulating hormone and luteinizing hormone increase $\mathrm{Ca} 2+$ in the granulosa cells of mouse ovarian follicles1. bioRxiv. Cold Spring Harbor Laboratory; 2019;520122.

48. Yeh T-S, Ho J-D, Yang VW-C, Tzeng C-R, Hsieh R-H. Calcium stimulates mitochondrial biogenesis in human granulosa cells. Ann NY Acad Sci. 2005;1042:157-62.

49. Arruda AP, Hotamisligil GS. Calcium homeostasis and organelle function in the pathogenesis of obesity and diabetes. Cell Metab. 2015:22:381-97.

50. Arruda AP, Pers BM, Parlakgül G, Güney E, Inouye K, Hotamisligil GS. Chronic enrichment of hepatic ER-mitochondria contact sites leads to calcium dependent mitochondrial dysfunction in obesity. Nat Med. 2014:20:1427-35.

51. Egnatchik RA, Leamy AK, Jacobson DA, Shiota M, Young JD. ER calcium release promotes mitochondrial dysfunction and hepatic cell lipotoxicity in response to palmitate overload. Mol Metab. 2014;3:544-53.

52. Fu S, Yang L, Li P, Hofmann O, Dicker L, Hide W, et al. Aberrant lipid metabolism disrupts calcium homeostasis causing liver endoplasmic reticulum stress in obesity. Nature. 2011;473:528-31.

53. Huang $\mathrm{JM}$, Xian $\mathrm{H}$, Bacaner $\mathrm{M}$. Long-chain fatty acids activate calcium channels in ventricular myocytes. Proc Natl Acad Sci U S A. 1992:89:6452-6.

54. Zhang J, Li Y, Jiang S, Yu H, An W. Enhanced endoplasmic reticulum SERCA activity by overexpression of hepatic stimulator substance gene prevents hepatic cells from ER stress-induced apoptosis. Am J Physiol Cell Physiol. 2014;306:C279-90.

55. Rossi A, Pizzo P, Filadi R. Calcium, mitochondria and cell metabolism: A functional triangle in bioenergetics. Biochim Biophys Acta Mol Cell Res. 2019:1866:1068-78. 
56. Wang $\mathrm{C}-\mathrm{H}$, Wei Y-H. Role of mitochondrial dysfunction and dysregulation of $\mathrm{Ca} 2+$ homeostasis in the pathophysiology of insulin resistance and type 2 diabetes. J Biomed Sci. 2017;24:70.

57. Rieusset J. Role of endoplasmic reticulum-mitochondria communication in type 2 diabetes. Adv Exp Med Biol. 2017;997:171-86.

58. Purcell SH, Chi MM, Lanzendorf S, Moley KH. Insulin-stimulated glucose uptake occurs in specialized cells within the cumulus oocyte complex. Endocrinology. 2012;153:2444-54.

59. Rice S, Pellatt LJ, Bryan SJ, Whitehead SA, Mason HD. Action of metformin on the insulin-signaling pathway and on glucose transport in human granulosa cells. J Clin Endocrinol Metab. 2011;96:E427-35.

60. Petersen MC, Shulman Gl. Roles of diacylglycerols and ceramides in hepatic insulin resistance. Trends Pharmacol Sci. 2017;38:649-65.

61. Summers SA. Ceramides in insulin resistance and lipotoxicity. Prog Lipid Res. 2006:45:42-72.

62. Guo Z, Yu Q. Role of mTOR signaling in female reproduction. Front Endocrinol. 2019;10:692.

63. Johnson AL, Bridgham JT, Swenson JA. Activation of the Akt/protein kinase $B$ signaling pathway is associated with granulosa cell survival. Biol Reprod. 2001;64:1566-74.

64. Puri P, Little-Ihrig L, Chandran U, Law NC, Hunzicker-Dunn M, Zeleznik AJ. Protein kinase A: a master kinase of granulosa cell differentiation. Sci Rep. 2016 [cited 2018 May 22];6. Available from: https://www.ncbi.nlm. nih.gov/pmc/articles/PMC4914995/.

65. Zeleznik AJ, Saxena D, Little-Ihrig L. Protein kinase B is obligatory for follicle-stimulating hormone-induced granulosa cell differentiation. Endocrinology. 2003;144:3985-94.

66. Shah DK, Missmer SA, Berry KF, Racowsky C, Ginsburg ES. Effect of obesity on oocyte and embryo quality in women undergoing in vitro fertilization. Obstet Gynecol. 2011;118:63-70.

67. Li X, Monks B, Ge Q, Birnbaum MJ. Akt/PKB regulates hepatic metabolism by directly inhibiting PGC-1alpha transcription coactivator. Nature. 2007:447:1012-6.

68. Yazawa T, Inaoka Y, Okada R, Mizutani T, Yamazaki Y, Usami Y, et al. PPAR-gamma coactivator-1alpha regulates progesterone production in ovarian granulosa cells with SF-1 and LRH-1. Mol Endocrinol Baltim Md. 2010;24:485-96.

69. Zhou Z, Wan Y, Zhang Y, Wang Z, Jia R, Fan Y, et al. Follicular development and expression of nuclear respiratory factor-1 and peroxisome proliferator-activated receptor $\gamma$ coactivator- 1 alpha in ovaries of fetal and neonatal doelings. J Anim Sci. 2012;90:3752-61.

70. Fernandez-Marcos PJ, Auwerx J. Regulation of PGC-1 a, a nodal regulator of mitochondrial biogenesis1234. Am J Clin Nutr. 2011;93:884S-90S.

71. Hajri T, Han XX, Bonen A, Abumrad NA. Defective fatty acid uptake modulates insulin responsiveness and metabolic responses to diet in CD36-null mice. J Clin Invest. 2002;109:1381-9.

72. Matschinsky FM, Wilson DF. The central role of glucokinase in glucose homeostasis: a perspective 50 years after demonstrating the presence of the enzyme in Islets of Langerhans. Front Physiol [Internet]. 2019 [cited 2020 Jul 8];10. Available from: https://www.ncbi.nlm.nih.gov/ pmc/articles/PMC6435959/.

73. Wicks SE, Vandanmagsar B, Haynie KR, Fuller SE, Warfel JD, Stephens JM, et al. Impaired mitochondrial fat oxidation induces adaptive remodeling of muscle metabolism. Proc Natl Acad Sci U S A. 2015;112:E3300-9.

74. Wu R-X, Dong Y-Y, Yang P-W, Wang L, Deng Y-H, Zhang H-W, et al. CD36and obesity-associated granulosa cells dysfunction. Reprod Fertil Dev. 2019;31:993-1001.

75. Hardie DG, Mackintosh RW. AMP-activated protein kinase - an archetypal protein kinase cascade? BioEssays. 1992;14:699-704

76. Carling D, Zammit VA, Hardie DG. A common bicyclic protein kinase cascade inactivates the regulatory enzymes of fatty acid and cholesterol biosynthesis. FEBS Lett. 1987;223:217-22.

77. Kola B, Grossman AB, Korbonits M. The role of AMP-activated protein kinase in obesity. Front Horm Res. 2008;36:198-211.

78. Richardson MC, Ingamells S, Simonis CD, Cameron IT, Sreekumar $\mathrm{R}$, Vijendren $\mathrm{A}$, et al. Stimulation of lactate production in human granulosa cells by metformin and potential involvement of adenosine 5 ' monophosphate-activated protein kinase. J Clin Endocrinol Metab. 2009;94:670-7.
79. Zhou G, Myers R, Li Y, Chen Y, Shen X, Fenyk-Melody J, et al. Role of AMP-activated protein kinase in mechanism of metformin action. J Clin Invest. 2001;108:1167-74.

80. Lyons CL, Roche HM. Nutritional Modulation of AMPK-Impact upon Metabolic-Inflammation. Int J Mol Sci. 2018;19:3092 Multidisciplinary Digital Publishing Institute.

81. Ruderman NB, Carling D, Prentki M, Cacicedo JM. AMPK, insulin resistance, and the metabolic syndrome. J Clin Invest. 2013;123:2764-72.

82. Bertoldo MJ, Faure M, Dupont J, Froment P. Impact of metformin on reproductive tissues: an overview from gametogenesis to gestation. Ann Transl Med. AME Publishing Company. 2014;2:5-5.

83. Kayampilly PP, Menon KMJ. AMPK activation by dihydrotestosterone reduces FSH-stimulated cell proliferation in rat granulosa cells by inhibiting ERK signaling pathway. Endocrinology. 2012;153:2831-8.

84. Tosca L, Crochet S, Ferré P, Foufelle F, Tesseraud S, Dupont J. AMPactivated protein kinase activation modulates progesterone secretion in granulosa cells from hen preovulatory follicles. J Endocrinol. BioScientifica. 2020;190:85-97.

85. Tosca L, Chabrolle C, Uzbekova S, Dupont J. Effects of metformin on bovine granulosa cells steroidogenesis: possible involvement of adenosine $5^{\prime}$ monophosphate-activated protein kinase (AMPK). Biol Reprod. 2007;76:368-78 Oxford Academic.

86. Mansfield R, Galea R, Brincat M, Hole D, Mason H. Metformin has direct effects on human ovarian steroidogenesis. Fertil Steril. 2003;79:956-62.

87. Maizels ET, Cottom J, Jones JC, Hunzicker-Dunn M. Follicle stimulating hormone (FSH) activates the p38 mitogen-activated protein kinase pathway, inducing small heat shock protein phosphorylation and cell rounding in immature rat ovarian granulosa cells. Endocrinology. 1998:139:3353-6.

88. Shiota M, Sugai N, Tamura M, Yamaguchi R, Fukushima N, Miyano T, et al. Correlation of mitogen-activated protein kinase activities with cell survival and apoptosis in porcine granulosa cells. Zoolog Sci. 2003;20:193-201.

89. Uma J, Muraly P, Verma-Kumar S, Medhamurthy R. Determination of onset of apoptosis in granulosa cells of the preovulatory follicles in the bonnet monkey (Macaca radiata): correlation with mitogenactivated protein kinase activities. Biol Reprod. 2003;69:1379-87 Oxford Academic.

90. Yu F-Q, Han C-S, Yang W, Jin X, Hu Z-Y, Liu Y-X. Activation of the p38 MAPK pathway by follicle-stimulating hormone regulates steroidogenesis in granulosa cells differentially. J Endocrinol. 2005;186:85-96.

91. Cao W-H, Xiong Y, Collins Q-F, Liu H-Y. p38 mitogen-activated protein kinase plays a critical role in the control of energy metabolism and development of cardiovascular diseases. Zhong Nan Da Xue Xue Bao Yi Xue Ban. 2007;32:1-14.

92. Collins QF, Xiong Y, Lupo EG, Liu H-Y, Cao W. p38 Mitogen-activated protein kinase mediates free fatty acid-induced gluconeogenesis in hepatocytes. J Biol Chem. 2006;281:24336-44.

93. Girard A, Dufort I, Douville G, Sirard M-A. Global gene expression in granulosa cells of growing, plateau and atretic dominant follicles in cattle. Reprod Biol Endocrinol. 2015;13:17.

94. Golini VE, Stradaioli G, Sirard MA. Transcriptome analysis of bovine granulosa cells of preovulatory follicles harvested 30,60,90, and 120 days postpartum. Theriogenology. 2014;82:580-591.e5.

95. Bosdou JK, Konstantinidou E, Anagnostis P, Kolibianakis EM, Goulis DG. Vitamin D and obesity: two interacting players in the field of infertility. Nutrients. 2019;11:1455 Multidisciplinary Digital Publishing Institute.

96. Bouillon R, Carmeliet G, Verlinden L, van Etten E, Verstuyf A, Luderer HF, et al. Vitamin $D$ and human health: lessons from vitamin $D$ receptor null mice. Endocr Rev. 2008;29:726-76.

97. Anagnostis P, Karras S, Goulis DG. Vitamin D in human reproduction: a narrative review. Int J Clin Pract. 2013;67:225-35.

98. Muscogiuri G, Policola C, Prioletta A, Sorice G, Mezza T, Lassandro A, et al. Low levels of 25(OH)D and insulin-resistance: 2 unrelated features or a cause-effect in PCOS? Clin Nutr Edinb Scotl. 2012;31:476-80.

99. Aghadavod E, Mollaei H, Nouri M, Hamishehkar H. Evaluation of relationship between body mass index with vitamin D receptor gene expression and vitamin D levels of follicular fluid in overweight patients with polycystic ovary syndrome. Int J Fertil Steril. 2017;11:105-11. 
100. Irani M, Merhi Z. Role of vitamin D in ovarian physiology and its implication in reproduction: a systematic review. Fertil Steril. 2014;102:460-468. e3.

101. Merhi Z, Doswell A, Krebs K, Cipolla M. Vitamin D alters genes involved in follicular development and steroidogenesis in human cumulus granulosa cells. J Clin Endocrinol Metab. 2014;99:E1137-45.

102. Parikh G, Varadinova M, Suwandhi P, Araki T, Rosenwaks Z, Poretsky L, et al. Vitamin D regulates steroidogenesis and insulin-like growth factor binding protein-1 (IGFBP-1) production in human ovarian cells. Horm Metab Res Horm Stoffwechselforschung Horm Metab. 2010;42:754-7.

103. Lolicato F, Brouwers JF, van de Lest CHA, Wubbolts R, Aardema H, Priore $P$, et al. The cumulus cell layer protects the bovine maturing oocyte against fatty acid-induced lipotoxicity1. Biol Reprod [Internet]. 2015 [cited 2021 Nov 23];92. https://doi.org/10.1095/biolreprod.114.120634

104. Silvestris E, de Pergola G, Rosania R, Loverro G. Obesity as disruptor of the female fertility. Reprod Biol Endocrinol. 2018;16:22.

105. Peng SL, Gerth AJ, Ranger AM, Glimcher LH. NFATC1 and NFATC2 together control both T and B cell activation and differentiation. Immunity. 2001;14:13-20.

106. Rao A, Luo C, Hogan PG. Transcription factors of the NFAT family: regulation and function. Annu Rev Immunol. 1997;15:707-47.

107. Ho IC, Kim JH, Rooney JW, Spiegelman BM, Glimcher LH. A potential role for the nuclear factor of activated T cells family of transcriptional regulatory proteins in adipogenesis. Proc Natl Acad Sci U S A. 1998;95:15537-41.

108. Yang TTC, Xiong Q, Enslen H, Davis RJ, Chow C-W. Phosphorylation of NFATc4 by p38 mitogen-activated protein kinases. Mol Cell Biol. 2002;22:3892-904.

109. Yang TTC, Suk HY, Yang X, Olabisi O, Yu RYL, Durand J, et al. Role of transcription factor NFAT in glucose and insulin homeostasis. Mol Cell Biol. 2006;26:7372-87.

110. Chen H, Yang Y, Wang Y, Li Y, He Y, Duan J, et al. Phospholipase C inhibits apoptosis of porcine primary granulosa cells cultured in vitro. J Ovarian Res. 2019;12:90

111. Filip M, Bader M. Overview on 5-HT receptors and their role in physiology and pathology of the central nervous system. Pharmacol Rep. 2009;61:761-77.

112. Bromfield JJ, Sheldon IM. Lipopolysaccharide initiates inflammation in bovine granulosa cells via the TLR4 pathway and perturbs oocyte meiotic progression in vitro. Endocrinology. 2011;152:5029-40.

113. Duffy DM, Ko C, Jo M, Brannstrom M, Curry TE. Ovulation: parallels with inflammatory processes. Endocr Rev. 2019;40:369-416 Oxford Academic.

114. Herath S, Williams EJ, Lilly ST, Gilbert RO, Dobson H, Bryant CE, et al. Ovarian follicular cells have innate immune capabilities that modulate their endocrine function. Reprod Camb Engl. 2007;134:683-93.

115. Adams J, Liu Z, Ren YA, Wun W-S, Zhou W, Kenigsberg S, et al. Enhanced inflammatory transcriptome in the granulosa cells of women with polycystic ovarian syndrome. J Clin Endocrinol Metab. 2016;101:3459-68.

116. Brannstrom M, Pascoe V, Norman RJ, McClure N. Localization of leukocyte subsets in the follicle wall and in the corpus luteum throughout the human menstrual cycle**Supported by a Queen Elizabeth Hospital Fellowships, Woodville, South Australia, and by grant 4982 from the Swedish Medical Research Council, Assar Gabrie Research Foundation, Tore Nilssons Foundation, and Goteborg Medical Society, Goteborg, Sweden. Fertil Steril. 1994;61:488-95.

117. Hellberg P, Thomsen P, Olof Janson P, Brännström M. Leukocyte supplementation increases the luteinizing hormone-induced ovulation rate in the in vitro-perfused rat ovary. Biol Reprod. 1991;44:791-7 Oxford Academic.

118. Schmidt J, Weijdegård B, Mikkelsen AL, Lindenberg S, Nilsson L, Brännström M. Differential expression of inflammation-related genes in the ovarian stroma and granulosa cells of PCOS women. Mol Hum Reprod. 2014;20:49-58.

119. Gorospe WC, Spangelo BL. Interleukin- 6 production by rat granulosa cells in vitro: effects of cytokines, follicle-stimulating hormone, and cyclic 3',5'-adenosine monophosphate. Biol Reprod. 1993;48:538-43.

120. La Vignera S, Condorelli R, Bellanca S, La Rosa B, Mousaví A, Busà B, et al. Obesity is associated with a higher level of pro-inflammatory cytokines in follicular fluid of women undergoing medically assisted procreation (PMA) programs. Eur Rev Med Pharmacol Sci. 2011;15:267-73.
121. Yang $M$, Wang $X$, Wang L, Wang $X$, Li J, Yang Z. IL-1 a Up-Regulates IL-6 expression in bovine granulosa cells via MAPKs and NF-KB signaling pathways. Cell Physiol Biochem Int J Exp Cell Physiol Biochem Pharmacol. 2017;41:265-73.

122. Duleba AJ, Dokras A. Is PCOS an inflammatory process? Fertil Steril. 2012;97:7-12 Elsevier.

123. Nteeba J, Ortinau LC, Perfield JW, Keating AF. Diet-induced obesity alters immune cell infiltration and expression of inflammatory cytokine genes in mouse ovarian and peri-ovarian adipose depot tissues. Mol Reprod Dev. 2013;80:948-58.

124. Samir M, Glister C, Mattar D, Laird M, Knight PG. Follicular expression of pro-inflammatory cytokines tumour necrosis factor-a (TNFa), interleukin 6 (IL6) and their receptors in cattle: TNFa, IL6 and macrophages suppress thecal androgen production in vitro. Reproduction. 2017;154:3549 Bioscientifica Ltd.

125. Kondo N, Nakamura H, Masutani H, Yodoi J. Redox regulation of human thioredoxin network. Antioxid Redox Signal. 2006;8:1881-90.

126. Igosheva N, Abramov AY, Poston L, Eckert JJ, Fleming TP, Duchen MR, et al. Maternal diet-induced obesity alters mitochondrial activity and redox status in mouse oocytes and zygotes. PLoS ONE [Internet]. 2010 [cited 2017 Jul 28];5. Available from: http://www.ncbi.nlm.nih.gov/pmc/ articles/PMC2852405/.

127. Shaeer EK, Soliman SA, El-Ghareeb AA. Obesity and follicular fluid oxidative stress: Relationship to ICSI outcome. Middle East Fertil Soc J. 2014;19:139-43.

128. Kishi I, Ohishi M, Akiba Y, Asada H, Konishi Y, Nakano M, et al. Thioredoxin, an antioxidant redox protein, in ovarian follicles of women undergoing in vitro fertilization. Endocr J. 2016;63:9-20.

129. Ruebel ML, Cotter M, Sims CR, Moutos DM, Badger TM, Cleves MA, et al. Obesity modulates inflammation and lipid metabolism oocyte gene expression: a single-cell transcriptome perspective. J Clin Endocrinol Metab. Oxford Academic. 2017;102:2029-38.

130. Traber MG, Stevens JF. Vitamins $C$ and E: beneficial effects from a mechanistic perspective. Free Radic Biol Med. 2011;51:1000-13.

131. Abdollahifar M-A, Azad N, Sajadi E, Shams Mofarahe Z, Zare F, Moradi A, et al. Vitamin C restores ovarian follicular reservation in a mouse model of aging. Anat Cell Biol. 2019;52:196-203.

132. Tilly JL, Tilly KI. Inhibitors of oxidative stress mimic the ability of folliclestimulating hormone to suppress apoptosis in cultured rat ovarian follicles. Endocrinology. 1995;136:242-52.

133. Zreik TG, Kodaman PH, Jones EE, Olive DL, Behrman H. Identification and characterization of an ascorbic acid transporter in human granulosa-lutein cells. Mol Hum Reprod. 1999;5:299-302 Oxford Academic.

134. Park J-I, Kim S-G, Chun J-S, Seo Y-M, Jeon M-J, Ohba M, et al. Activation of protein kinase Czeta mediates luteinizing hormone- or forskolininduced NGFI-B expression in preovulatory granulosa cells of rat ovary. Mol Cell Endocrinol. 2007;270:79-86.

135. Liu T, Zhang L, Joo D, Sun S-C. NF-kB signaling in inflammation. Signal Transduct Target Ther. 2017;2:1-9 Nature Publishing Group.

136. Shih VF-S, Tsui R, Caldwell A, Hoffmann A. A single NFKB system for both canonical and non-canonical signaling. Cell Res. 2011;21:86-102.

137. Razani B, Reichardt AD, Cheng G. Non-canonical NF-kB signaling activation and regulation: principles and perspectives. Immunol Rev. 2011;244:44-54.

138. Gao H, Lin L, Haq IU, Zeng S-M. Inhibition of NF-kB promotes autophagy via JNK signaling pathway in porcine granulosa cells. Biochem Biophys Res Commun. 2016:473:311-6.

139. Valdez KE, Turzillo AM. Regulation of nuclear factor-KB (NF-KB) activity and apoptosis by estradiol in bovine granulosa cells. Mol Cell Endocrinol. 2005;243:66-73.

140. Wang Y, Chan S, Tsang BK. Involvement of inhibitory nuclear factor-kappaB (NFkappaB)-independent NFkappaB activation in the gonadotropic regulation of $X$-linked inhibitor of apoptosis expression during ovarian follicular development in vitro. Endocrinology. 2002;143:2732-40.

141. Xiao CW, Ash K, Tsang BK. Nuclear factor-kappaB-mediated X-linked inhibitor of apoptosis protein expression prevents rat granulosa cells from tumor necrosis factor alpha-induced apoptosis. Endocrinology. 2001;142:557-63.

142. Yuan X, Li Z, Kong Y, Zhong Y, He Y, Zhang A, et al. P65 targets FGFR1 to regulate the survival of ovarian granulosa cells. Cells. 2019;8:1334 Multidisciplinary Digital Publishing Institute. 
143. Yuan S, Wen J, Cheng J, Shen W, Zhou S, Yan W, et al. Age-associated up-regulation of EGR1 promotes granulosa cell apoptosis during follicle atresia in mice through the NF-kB pathway. Cell Cycle. 2016;15:2895-905.

144. Hayden MS, Ghosh S. Regulation of NF-kB by TNF family cytokines. Semin Immunol. 2014;26:253-66.

145. Coquery CM, Erickson LD. Regulatory roles of the tumor necrosis factor receptor BCMA. Crit Rev Immunol. 2012;32:287-305.

146. Marsters SA, Yan M, Pitti RM, Haas PE, Dixit VM, Ashkenazi A. Interaction of the TNF homologues BLyS and APRIL with the TNF receptor homologues BCMA and TACl. Curr Biol. 2000;10:785-8 Elsevier.

147. Park S-R, Kim P-H, Lee K-S, Lee S-H, Seo G-Y, Yoo Y-C, et al. APRIL stimulates NF-KB-mediated HoxC4 induction for AID expression in mouse B cells. Cytokine. 2013;61:608-13.

148. Xu J, Ding WF, Shao KK, Wang XD, Wang GH, Li HQ, et al. Transcription of promoter from the human APRIL gene regulated by Sp1 and NF-kB. Neoplasma. 2012;59:341-7.

149. Yamamoto H, Kishimoto T, Minamoto S. NF-kB Activation in CD27 Signaling: Involvement of TNF Receptor-Associated Factors in Its Signaling and Identification of Functional Region of CD27. J Immunol. 1998;161:4753-9 American Association of Immunologists.

150. Snider AP, Wood JR. Obesity induces ovarian inflammation and reduces oocyte quality. Reproduction. 2019;158:R79-90 Bioscientifica Ltd.

151. Havelock JC, Rainey WE, Carr BR. Ovarian granulosa cell lines. Mol Cell Endocrinol. 2004;228:67-78.

\section{Publisher's Note}

Springer Nature remains neutral with regard to jurisdictional claims in published maps and institutional affiliations.

- fast, convenient online submission

- thorough peer review by experienced researchers in your field

- rapid publication on acceptance

- support for research data, including large and complex data types

- gold Open Access which fosters wider collaboration and increased citations

- maximum visibility for your research: over 100M website views per year

At BMC, research is always in progress.

Learn more biomedcentral.com/submissions 